\title{
Trauma networks: present and future challenges
}

\author{
Nikolaos K Kanakaris and Peter V Giannoudis ${ }^{*}$
}

\begin{abstract}
In England, trauma is the leading cause of death across all age groups, with over 16,000 deaths per year. Major trauma implies the presence of multiple, serious injuries that could result in death or serious disability. Successive reports have documented the fact that the current ad hoc unstructured management of this patient group is associated with considerable avoidable death and disability. The reform of trauma care in England, especially of the severely injured patient, has already begun. Strong clinical leadership is embraced as the way forward. The present article summarises the steps that have been made over the last decade that led to the recent decision to move towards a long anticipated restructure of the National Health Service (NHS) trauma services with the introduction of Regional Trauma Networks (RTNs). While, for the first time, a genuine political will and support exists, the changes required to maintain the momentum for the implementation of the RTNs needs to be marshalled against arguments, myths and perceptions from the past. Such an approach may reverse the disinterest attitude of many, and will gradually evolve into a cultural shift of the public, clinicians and policymakers in the fullness of time.
\end{abstract}

\section{Background}

Trauma consists of a wide spectrum of clinical conditions that are initiated in the immediate aftermath following injury. In England, trauma is the leading cause of death across all age groups, with over 16,000 deaths per year. It is one of the few diseasecategories in which mortality is increasing [1-5].

The term 'major trauma' is used to describe a serious clinical state of injured patients, and often implies the simultaneous presence of multiple injuries to the same or different body regions and systems [6]. For the purposes of a healthcare system, it also includes any injury so complex that it exceeds the capabilities or expertise of the receiving health unit [7]. From the health economic aspect point of view, 'multiple trauma' or 'polytrauma' is represented by Healthcare Resource Groups (HRG)-4 codes (subchapter VA; 8 different codes), whereas from a clinical research point of view it is defined as an injury severity score (ISS) of more than 16 in the presence of more than 1 injury $[8,9]$. Irrespective of the differing definitions, limitations and disparity, major trauma is proven to affect $15 \%$ of all injured patients; less than 2 per 1,000 emergency department admissions, around 30 cases per 100,000 of population per year [7]. It is the sixth highest overall leading cause

\footnotetext{
* Correspondence: pgiannoudi@aol.com

Academic Department of Trauma and Orthopaedics, Leeds General Infirmary, Clarendon Wing, Level A, Great George Street, LS13EX, Leeds, UK
}

of death and fifth highest cause of disability in all age groups across the globe [10]. In England there are at least 20,000 such cases annually, which are managed in 193 different hospitals, with an estimated cost of $£ 0.3$ to $£ 0.4$ billion per year [6].

Successive reports (Table 1) have documented the fact that the current ad hoc unstructured management of this patient group is associated with considerable avoidable death and disability. The high acuity and need for trauma readiness around the clock, the reality of delayed secondary transfers, and the justified severe criticism of the currently offered care and waste of resources all set the scene for an urgently needed reformat of trauma services in the England [6,11-38].

The crude numbers representing the huge burden of trauma, the increasing public awareness of the issue, and the documented underperformance of the existing UK trauma services, eventually led to the recent decision for a long anticipated restructure of the National Health Service (NHS) trauma services. The present article aims to summarise the steps that have been taken over the last decade, culminating in the formation of Regional Trauma Networks (RTNs) nationally, as well as highlighting foreseeable future challenges.

\section{RTN rationale}

The numerous official reports, mainly at a national level $[6,11-13,15,19,20,25,26,28-31,39,40]$, and the 
Table 1 Calendar of related past events

\begin{tabular}{|c|c|c|}
\hline Source, year & Statement & Recommendation \\
\hline $\begin{array}{l}\text { Osmond-Clark H, } \\
\text { 1961-1975 } \\
\text { [11-13] }\end{array}$ & $\begin{array}{l}\text { 'Casualty department' staffed by casualty officers, usually senior } \\
\text { house officers (SHOs) who had been qualified for } 1 \text { or } 2 \text { years. } \\
\text { Senior cover was negligible. }\end{array}$ & $\begin{array}{l}\text { Tripartite scheme of peripheral casualty units, DGH accident } \\
\text { centres and a regional major injury unit serving a population of } \\
1 \text { to } 2 \text { million }\end{array}$ \\
\hline $\begin{array}{l}\text { Cales RH and } \\
\text { Trunkey DD, } \\
1985[14]\end{array}$ & $\begin{array}{l}\text { Effect of a regional trauma system in reducing trauma mortality } \\
\text { (USA) }\end{array}$ & $\begin{array}{l}\text { Use of 'preventable trauma deaths' as an evaluation tool of } \\
\text { effectiveness }\end{array}$ \\
\hline $\begin{array}{l}\text { RCSE report, } \\
1988[15]\end{array}$ & $\begin{array}{l}\text { Great discrepancy and deficiencies in existing emergency } \\
\text { services. Serious deficiencies in the management of seriously } \\
\text { injured patients. }\end{array}$ & $\begin{array}{l}\text { Establishment of trauma centres. Introduction of ATLS in the } \\
\text { UK. Three pilot trauma centres in the UK (Royal London } \\
\text { Hospital, the John Radcliffe Hospital in Oxford and North- } \\
\text { Staffordshire Hospital in Stoke). }\end{array}$ \\
\hline $\begin{array}{l}\text { Anderson ID, } \\
1988[16]\end{array}$ & Preventable trauma deaths over 33\% in England and Wales & Need for changes in trauma-related services \\
\hline $\begin{array}{l}\text { BOA report, } \\
1989[17]\end{array}$ & $\begin{array}{l}\text { Too many small units and too few consultants with a special } \\
\text { interest in trauma care. Considerable resource implications of }\end{array}$ & $\begin{array}{l}\text { Services should be concentrated. Need for expansion of } \\
\text { consultant numbers. }\end{array}$ \\
\hline
\end{tabular}

\begin{tabular}{lll}
\hline $\begin{array}{l}\text { Redmond AD, } \\
1991[18]\end{array}$ & $\begin{array}{l}\text { First trauma centre in the UK (North Staffordshire Hospital } \\
\text { Centre). Cost effectiveness and appropriateness evaluation. }\end{array}$ & Use of pilot programmes to template needed changes \\
\hline $\begin{array}{l}\text { NAO report, } \\
1992[19]\end{array}$ & $\begin{array}{l}\text { Deficiencies in NHS Accident and Emergency (A\&E) } \\
\text { Departments in England }\end{array}$ & $\begin{array}{l}\text { Information and Actions are required. Early and continuing } \\
\text { improvements are needed. How trauma audit should be taken } \\
\text { forward. }\end{array}$ \\
\hline
\end{tabular}

BOA report, Review of 263 hospitals in the UK identified deficiencies in staff Need for Regional Trauma Centre with its multidisciplinary 1992 [20] and equipment. Trauma services had not kept pace with technical advances. Many units were too small to sustain an adequate standard of care. arrangements. Set standards for the facilities required in a DGH. Rapid transfer to suitable hospital. Direct involvement of senior clinicians.

MTOS Study, Initial resuscitation by junior staff in more than $50 \%$ of the

Yates DW et al., cases. Delays in providing experienced staff and timely

1992 [21] operations. Mortality varies inexplicably between hospitals. Significantly higher mortality rate for blunt trauma than in the US.

UK-TARN Creation of Data Collection Network related to trauma

Recording performance and allowing the rationalisation of

formation, 1993

Creation of Data Collection Network related to trauma

implemented changes to the trauma services

[22]

Rowley DI, 1993 Lack of A\&E consultants (21\%). Lack of vital trauma associated Reformation of trauma services. Early senior staff involvement.

[23] specialties (80\%). Lack of intensive care facilities (6\%).

Nicholl $\mathrm{J}$ and Evaluation of pilot trauma centre and regional network showed Greater integration along the entire trauma care pathway is the

Turner J, 1997 modest reductions in mortality priority

[24]

$\mathrm{BOA}$ report, $\quad$ Lower quality of care in comparison to countries such as

1997 [25] Germany, Switzerland and the USA

BOA and RCSE Current system does not assess the quality of life of those that joint report, survive. Only 50\% of Trusts subscribe to TARN.

2000 [26]

\section{An integrated network approach to treating trauma patients.} Integrated approach based upon a hub and spoke model.

Lecky FE, et al., Lack of significant improvement in case fatality reduction

2002 [27] between 1994 and 2000 according to the UK-TARN data

NAO report, Trauma audit has been improved through the establishment of Further expansion of the national TARN network. Development

2004 [28] TARN. Still scope for this work to be developed at a regional of Regional services. level

NCEPOD report, Deficiencies in both the organisational and clinical aspects of

2007 [6] trauma care. Organisation of prehospital care, trauma team response, seniority of staff involvement and immediate inhospital care was found to be deficient. Less than good care for $60 \%$ of reviewed major trauma patients.

Lord Darzi's Review of London's healthcare identified stark of inequalities in

London report, health outcomes and the quality and safety of patient care not

2007 [29] as good as it could, and should, be

Need for designated Level 1 trauma centres. Ensure that a trauma team is available 24/7. A consultant must be the team leader for the management of the severely injured patient.

Need for nationally coordinated standards of care. Need for
systematic audit. Need for the development of outcome measures. Need for geographical trauma systems. Need for a strategy for rehabilitation.

Lord Darzi's Review of the NHS identified compelling arguments for saving report, 2008 [30] lives by creating specialised centres for major trauma. SHA are

asked to begin considering major trauma services.

A trauma system should be put into operation within London. Integration of hospital and prehospital care. Bypass protocols need to be traduced taking the most seriously ill directly to trauma centres.

Create specialised centres for major trauma. Development of regional plans from strategic health authorities 


\section{Table 1 Calendar of related past events (Continued)}

\begin{tabular}{|c|c|c|}
\hline $\begin{array}{l}\text { RCSE report, } \\
2009[31]\end{array}$ & $\begin{array}{l}\text { Without regionalisation, trauma mortality and morbidity in the } \\
\text { UK will remain unacceptably high. The likelihood of dying from } \\
\text { injuries has remained static since } 1994 \text { despite improvements in } \\
\text { trauma care, education and training. }\end{array}$ & $\begin{array}{l}\text { Individual SHAs need to interpret the guidance to meet their } \\
\text { own needs. There is no 'fit-all' scenario. Further development is } \\
\text { urgently needed regarding areas as paediatric trauma care, } \\
\text { burns care and rehabilitation services. }\end{array}$ \\
\hline $\begin{array}{l}\text { Professor Keith } \\
\text { Willett, } 2009\end{array}$ & $\begin{array}{l}\text { Department of Health appoints a National Clinical Director for } \\
\text { Trauma care for the first time. }\end{array}$ & $\begin{array}{l}\text { National leadership for the implementation of regional trauma } \\
\text { networks in England. Commissioning, audit, modelling, metrics, } \\
\text { standards, critical care capacity, interventional radiology, } \\
\text { rehabilitation, behavioural change, workforce, and training } \\
\text { needs. }\end{array}$ \\
\hline $\begin{array}{l}\text { Dr Fiona Moore, } \\
2009\end{array}$ & Healthcare for London appoints London's first Trauma Director & $\begin{array}{l}\text { Responsible for leading the implementation of new specialist } \\
\text { trauma networks across the capital }\end{array}$ \\
\hline $\begin{array}{l}\text { NAO report, } \\
2010 \text { [19] }\end{array}$ & $\begin{array}{l}\text { Significant data gaps and a lack of formalised systems remain. } \\
\text { Still 59\% of hospitals delivering trauma care participate in UK } \\
\text { TARN. Major trauma care cannot be delivered cost effectively by } \\
\text { all hospitals. Only one hospital has consultant lead services 24/ } \\
\text { 7. A total of 64\% of major trauma patients do not receive } \\
\text { specialist care. Unacceptable variations in mortality rates, } \\
\text { depending on where and when a person receives treatment. } \\
\text { Lack of adequate data on level of rehabilitation services. Current } \\
\text { funding arrangements do not reflect the actual trauma costs. }\end{array}$ & $\begin{array}{l}\text { SHA to develop regional trauma networks. Designation of } \\
\text { hospitals suitable to receive major trauma cases. The DoH to } \\
\text { review the financial levers of delivery of major trauma care. }\end{array}$ \\
\hline $\begin{array}{l}\text { London } \\
\text { Network, } 2010 \\
{[32]}\end{array}$ & $\begin{array}{l}\text { Initiation of the first comprehensive Trauma Network of the UK. } \\
\text { Major Trauma Centres: The Royal London Hospital } \\
\text { (Whitechapel), St George's Hospital (Tooting), King's College } \\
\text { Hospital (Denmark Hill) and St Mary's Hospital (Paddington). }\end{array}$ & $\begin{array}{l}\text { Act also as a template for the development of the Regional } \\
\text { Trauma Networks across the UK }\end{array}$ \\
\hline $\begin{array}{l}\text { Davenport DA, } \\
\text { et al., } 2010 \text { [33] }\end{array}$ & $\begin{array}{l}\text { The effect of the reform of trauma services at RLH and the } \\
\text { introduction of a MDT trauma service in } 2003 \text { was identified to } \\
\text { have reduced preventable deaths from } 9 \% \text { to } 2 \% \text {, and } \\
\text { secondary transfer mortality by } 53 \% \text { versus the national average. } \\
\text { Implementation of a specialist trauma service and performance } \\
\text { improvement programme is associated with rapid reductions in } \\
\text { mortality for the severely injured. }\end{array}$ & $\begin{array}{l}\text { Future national major trauma centres should be specialist } \\
\text { hospitals, not simply hospitals with specialties }\end{array}$ \\
\hline $\begin{array}{l}\text { East Midlands } \\
\text { Network, } 2011\end{array}$ & $\begin{array}{l}\text { Nottingham to be the first major trauma centre to start } \\
\text { functioning outside London }\end{array}$ & $\begin{array}{l}\text { Act also as a template for the development of the Regional } \\
\text { Trauma Networks across the UK }\end{array}$ \\
\hline
\end{tabular}

$\mathrm{BOA}=$ British Orthopaedic, Association, DGH = District General Hospital, DoH = Department of Health, MDT = multidisciplinary team, MTOS = Major Trauma Outcome Study, NAO = National Audit Office, NCEPOD = National Confidential Enquiry into Patient Outcome and Death; NHS = National Health Service; RCSE = Royal College of Surgeons of England; RLH = Royal London Hospital; SHA = Strategic Health Authorities; TARN = Trauma Audit and Research Network.

accumulation of significant international experience [41-50] advocating organised networks of trauma care covering defined geographic regions, led to the recent evolution and maturation of decision making towards the formation of such a system in the UK. This challenging task was assigned by the Department of Health (DoH) to the Strategic Health Authorities (SHAs) in 2009 following the review of healthcare by the then Health Minister Lord Darzi [30]. The London and East Midlands areas have already gone a long way to completing their operational plan and will be used as pilots for the rest of the SHAs. The planning and designing of all networks by 2010-2011, and their implementation throughout the 2011-2012 financial year, was the original plan of the $\mathrm{DoH}$ and steps are rapidly being taken by all stakeholders to meet these deadlines.

The 'ideal' RTN is a complex all-inclusive system of trauma-related services, from prehospital care through to acute care and rehabilitation. It affects and is affected by numerous patient and healthcare-related parameters, as well as legislation and finances [51]. The goal is to match the utilised resources of the provider to the needs of the injured patients at the appropriate facility in a timely manner, achieving optimal management from the initial recognition of the injury to the return of the patient to the community.

A wholesale introduction of an American type of system does not appear suitable for the UK due to the presence of many densely populated areas, shorter transportation distances, and the already existing infrastructure and role of district general hospitals $[24,26,31,35,37,39]$. Nevertheless, the description of the fundamental components of a RTN made by the Committee on Trauma of the American College of Surgeons fully applies to the recently introduced UK model. They consist of: leadership (at all levels of trauma care delivery), trauma care facilities (major trauma centres, trauma units, transport services, rehabilitation units), human resources (planning and development, administrative and clinical teamwork), education-preventionpublic awareness (information on the trauma system, communication pathways with primary care and the 
public), triage-transport means, interhospital transfers, communication network (at all levels of the trauma system), rehabilitation, and data collection and quality assurance monitoring [41].

The appointment for the first time of a National Clinical Director in 2009, and the subsequent appointment of London's Trauma Director, reflect the importance given to inspired and clinically experienced leadership at the highest level of planning, decision making and coordination. It signifies the fact that the reformation of trauma in the UK is finally being taken seriously. The role of leadership transects all through the pyramid of the introduced trauma system, with the assignment of regional and local trauma leaders with administrative and clinical representation at all levels.

Trauma care will be provided within the network, structured in different tiers of applied resources, ranging between trauma units and major trauma centres, based on each patient's need. The assignment of roles and subsequent accreditation and revalidation of trauma hospitals to the different tiers has been initiated by each SHA and local clinical advisory boards. One or more major trauma centres (MTCs) will be identified in each region by the SHA according to specific criteria (Table 2). The Royal College of Surgeons of England [52] recommended the allocation of one MTC for every 3-4 million inhabitants based on particular geographic and population characteristics as well as comprehensive evidence on the correlation of outcome to the trauma centre's volume [53,54], making a total number of 12-16 across England.

Each MTC will be collaborating with a number of other hospitals delivering trauma care for less complex cases (trauma units (TUs)). These TUs will also be identified within each SHA in collaboration with Primary Care Trusts (PCTs)/Primary Care Consortiums, and assigned the management of less complex injuries, providing mostly limited and selected trauma care. At a third level, local hospitals will continue to provide existing emergency department services for minor injuries. The relationship and collaboration of the different healthcare facilities of different levels within the same regional network (MTC and TUs) is assured from the first phase of designation. Each SHA is responsible for facilitating and coordinating the establishment of robust communication pathways, and all stakeholders need to appreciate the vital role of collaboration at all levels. Existing pathways between hospitals and health services under the current secondary/tertiary referral system may also be utilised as scaffolds for the future RTN structure. Major threats of failure of this proposed RTN structure include congestion of the MTCs and segmentation of patient care between the MTC, peripheral units and rehabilitation [31].
The existing practice of consultant-led resuscitation available mostly in working hours will change to a 24-h consultant presence 7 days a week in all MTCs. Equally, consultant-led services will be available in a short timeframe post admission for all relevant surgical specialties (Table 2). Obvious requirements for the appointment of Accident and Emergency (A\&E) consultants, traumaoriented surgical specialists, as well as the recruitment of all necessary human resources and assets, are being addressed urgently in all SHAs and Trusts. Administrative and clinical personnel focused specifically on the care of the injured patients appear to be a major shift in health-related human resources over the last few years. To that end, institutions that have been already functioning as tertiary referral centres have the highest chance of becoming MTCs or TUs, making the selection process by the SHAs less difficult.

Trauma-related technical skills, training and professional education has been mostly provided by medical colleges, including courses for surgeons and other clinicians via the Advanced Trauma Life Support (ATLS) course, and for paramedics via the Pre-Hospital Trauma Life Support (PHTLS) course, which have withstood the test of time and have proven invaluable [31]. Further exposure and educational opportunities are currently available and will be explored, mostly related to the experience gained from the military and its advanced practices [55-58]. Education, however, should expand to include development of non-technical skills (leadership, communication, situation awareness, teamwork) $[59,60]$, as well as addressing the necessity for increased public awareness and prevention measures. Primary Care Trusts and the public must be active participants in the RTN. They need to be informed of the ways to access it, collaborate with relevant individuals and professional groups within it, and how to interact and participate in its preservation and improvement. The London and East Midlands SHAs have incorporated these aspects of public training and interaction $[32,61]$ and their experience will be useful in the development of further networks across the country.

Specific triage protocols have been introduced in London to support decisions regarding which patients should be taken to the MTC on the basis of an assessment of patient physiology (vital signs, consciousness), anatomy of apparent injuries, mechanism of injury, and individual patient factors (for example, age extremes, pregnancy, obesity) [32]. An anticipated overtriage of patients towards the MTCs is expected, but with time and with all the appropriate measures in place it is envisaged that this concern will be addressed. The role of the regional Ambulance Services in the specific design and implementation of these screening tools is essential. Each SHA is expected to involve them, as well as the 
Table 2 Essential characteristics of hospitals delivering trauma care in the Regional Trauma Network (RTN) era Characteristic Types of Institutions offering care to injured patients Major trauma centre (MTC) Trauma unit (TU)

\begin{tabular}{|c|c|c|}
\hline Total no. for England & $12-16$ & $80-100$ \\
\hline \multicolumn{3}{|l|}{ Administration/governance: } \\
\hline $\begin{array}{l}\text { Commitment from executive team } \\
\text { administration and senior clinical staff to } \\
\text { deliver such services }\end{array}$ & $100 \%$ & $100 \%$ \\
\hline $\begin{array}{l}\text { Clinical director for trauma, programme } \\
\text { manager and data manager }\end{array}$ & $100 \%$ & $100 \%$ \\
\hline Full dataset submission to TARN & $100 \%$ & $100 \%$ \\
\hline $\begin{array}{l}\text { Commitment to RTN, trauma governance, } \\
\text { continuous improvement }\end{array}$ & $100 \%$ & $100 \%$ \\
\hline $\begin{array}{l}\text { Critically injured patients (complex or major } \\
\text { trauma) }\end{array}$ & $>250$ per year & $\begin{array}{l}\text { Only for few cases when the bypass protocols are } \\
\text { not followed (patient in extremis, accident in the } \\
\text { premises of TU) }\end{array}$ \\
\hline \multicolumn{3}{|c|}{ Accident and emergency (A\&E): early resuscitation: } \\
\hline A\&E availability & $24 / 7$ & $24 / 7$ \\
\hline Resuscitation trauma team leader & Consultant 24/7 resident & $\begin{array}{l}\text { Experienced middle grade } 24 / 7 \text { resident; consultant } \\
\text { on call }{ }^{\mathrm{a}}\end{array}$ \\
\hline $\begin{array}{l}\text { Fully staffed with specialist nursing and } \\
\text { allied health professionals }\end{array}$ & $24 / 7$ & $24 / 7$ \\
\hline Band 7 nurse: specialist ED trauma nursing & $24 / 7$ & Variable \\
\hline $\begin{array}{l}\text { Activation protocols: established prealert } \\
\text { pathways }\end{array}$ & $24 / 7$ & $24 / 7$ \\
\hline \multicolumn{3}{|l|}{ Trauma service: } \\
\hline $\begin{array}{l}\text { Ongoing patient care post initial } \\
\text { resuscitation }\end{array}$ & Consultant on call $^{a}$ & Consultant on call ${ }^{a}$ \\
\hline Admission under a named consultant & Consultant on call $^{a}$ & Consultant on call $^{a}$ \\
\hline $\begin{array}{l}\text { Consultant-led service for ongoing } \\
\text { coordination of the care of major trauma } \\
\text { patients }\end{array}$ & Consultant on call ${ }^{a}$ & Consultant on call ${ }^{\mathrm{a}}$ \\
\hline Trauma nurse coordinator & Yes & Variable \\
\hline Radiology: (X-ray/FAST-CT) & Reporting within $24 \mathrm{~h}$ & Reporting within $24 \mathrm{~h}$ \\
\hline Available high specification CT scanner & $24 / 7$ & $24 / 7^{\mathrm{a}}$ \\
\hline Staffed laboratory services & $24 / 7$ & $24 / 7$ \\
\hline Blood bank & $24 / 7$ & $24 / 7$ \\
\hline Massive transfusion protocol & $24 / 7$ & $24 / 7$ \\
\hline Trauma and orthopaedic & $\begin{array}{l}\text { Middle grade resident, consultant on call }{ }^{\mathrm{a}} \text {, pelvic } \\
\text { reconstruction service, complex limb } \\
\text { reconstruction service }\end{array}$ & Middle grade resident, consultant on call ${ }^{a}$ \\
\hline General surgery & Middle grade resident, consultant on call ${ }^{\mathrm{a}}$ & Middle grade resident, consultant on call ${ }^{a}$ \\
\hline Neurosurgery & Middle grade resident, consultant on call ${ }^{a}$ & Variable \\
\hline Spinal surgery & Middle grade on call ${ }^{\mathrm{a}}$, consultant on call ${ }^{\mathrm{a}}$ & Variable \\
\hline Vascular surgery & Middle grade resident, consultant on call ${ }^{a}$ & Middle grade resident, consultant on call ${ }^{a}$ \\
\hline Anaesthetist & $\begin{array}{l}\text { Middle grade resident, consultant on call }{ }^{a} \text {; ODP } \\
\text { support within resuscitation }\end{array}$ & Middle grade resident, consultant on call ${ }^{a}$ \\
\hline Plastic surgery & Middle grade on call ${ }^{\mathrm{a}}$, consultant on call ${ }^{\mathrm{a}}$ & Variable \\
\hline Urology & Middle grade on call ${ }^{\mathrm{a}}$, consultant on call ${ }^{\mathrm{a}}$ & Variable \\
\hline Cardio/thoracic surgery & Middle grade on call ${ }^{\mathrm{a}}$, consultant on call ${ }^{\mathrm{a}}$ & Variable \\
\hline Maxillofacial/head and neck & Middle grade on call ${ }^{a}$, consultant on call ${ }^{a}$ & Variable \\
\hline Interventional radiology & Angio suite available $24 / 7^{\mathrm{a}}$, consultant on call ${ }^{\mathrm{a}}$ & Variable \\
\hline Dedicated trauma theatres, operating lists & $\begin{array}{l}\text { Immediately available, ability for second if } \\
\text { overwhelmed }\end{array}$ & $\begin{array}{l}\text { Immediately available, ability for second if } \\
\text { overwhelmed }\end{array}$ \\
\hline
\end{tabular}


Table 2 Essential characteristics of hospitals delivering trauma care in the Regional Trauma Network (RTN) era (Continued)

\begin{tabular}{lll}
\hline Intensive care facilities & $24 / 7$ & $24 / 7$ \\
\hline Critical care & Middle grade resident, consultant on call ${ }^{\text {a }}$ & Middle grade resident, consultant on call $^{\text {a }}$ \\
\hline Miscellaneous: & & Variable \\
\hline Education-prevention-research programmes & $100 \%$ & $100 \%$ \\
\hline Clinical governance programmes & $100 \%$ & $100 \%$ \\
\hline Interhospital transfer protocols & $100 \%$ & $100 \%$ \\
\hline Trauma rehabilitation programmes & $100 \%$ & \\
\hline${ }^{a}$ Available in 30 min. & & \\
$C T=$ computed tomography; ODP $=$ operating department practitioner.
\end{tabular}

rest of the stakeholders, taking into consideration local parameters in each region.

Transportation of trauma cases to the appropriate hospital in the network will become effective via the standard ambulance land and air services. Modern screening protocols, coordination by senior clinicians, and rationalisation of the geographic distribution of the TUs and the MTC(s) in each region is expected to secure the delivery of the appropriate level of care at the appropriate time for every injured patient. An acceptable transportation time within $30-45 \mathrm{~min}$ is expected to have minimal adverse effect on the outcome of trauma cases [41], as long as ambulance paramedic personnel are well trained and equipped, and the receiving hospital is of the appropriated level for the patient's needs.

As identified mostly from the interaction with public and the PCTs from the London and East Midlands pilot work, the support of families and carers, availability of counselling services, involvement of the above in the decisions about continuum of care and choice of TU to be transferred to post MTC hospitalisation, are of great importance. Patients should be taken to the bestequipped hospital for their particular injury, even if this means a slightly longer journey. MTCs must also fulfil minimum requirements of easy access in terms of public transportation, parking, accommodation and childcare. Each RTN must optimise all these parameters for the patients and their carers, making the whole experience of trauma care less stressful [31,32,37,39,61].

Robust communication systems and pathways are another of the major pillars of the designed RTNs. Direct access lines and around the clock, readily-available contacts will be accessible to all relevant stakeholders. It will ensure the continuity of care between MTC, TUs, rehabilitation units and general practitioner (GP) consortiums.

The current status of underprovision of rehabilitation services, especially to major trauma patients, is expected to be reversed by prompt engagement of these highdemand cases with complex and specialist rehabilitation practitioners. A more centralised rehabilitation framework with synchronisation of all the available resources is desirable, which would allow a more selfdirected therapy based on the individual demands of the patient [36]. Rehabilitation will start intensively from the acute phase, and continue uninterrupted following patient repatriation. Inevitably, redistribution of the available human and material resources, as well as additional specialists and infrastructure facilities, will be required. At a local level the early engagement of all stakeholders from all different trauma-related groups is initiated. The identification of the currently available capacity across the span of each region and the prerequisites for each individual health facility to function in its regional network is also underway. Specific workgroups in each SHA have been formed over the last year to ascertain the methodology and keep to the tight timelines. Effective leadership will be needed to drive the rehabilitation of major trauma patients within and outside the hospital setting from the early stages of their admission. Patients will be given a prescription for rehabilitation and specialised personnel will be involved from the very early stages, coordinating the overall rehabilitation course of each patient, preventing delays and optimising the final outcome. Directories of available rehabilitation services and contacts across each RTN will be developed to accommodate this increased workload [62].

Data currently collected by the Trauma Audit and Research Network (TARN) has matured over the last two decades and is expected to expand and incorporate all trauma-care-providing hospitals. Specific steps and plans have been made to erase existing financial or structural arguments for non-participation in the TARN family. In the fast-approaching new era, all hospitals participating in each trauma network will by default contribute to the TARN data collection, and are expected to work together sharing data collection assets and personnel. The new tariff for major trauma being developed by the $\mathrm{DoH}$ is expected to include an uplift to cover the cost of TARN membership [62]. The currently-collected information includes all the key 
observations, investigations and interventions through the patient's pathway, details on the injury mechanism, and injury descriptions that allow the assignment of injury scores and outcome on discharge from about $90 \%$ of England's trauma-receiving hospitals [63]. The recorded data include all patients that sustained a traumatic injury and whose length of stay was $72 \mathrm{~h}$ or more and/or all trauma-related deaths, admissions to intensive care units (ICUs)/high-dependency units (HDUs), and/ or transfers from another hospital for specialist care. The expectation is to achieve $100 \%$ of compliance and submission of data from all hospitals participating in the RTN by the end of 2011 [63]. In parallel, the DoH and the TARN are expected to develop measures of outcome additional to the evidence collected from TARN that will cover the entire pathway of the injured patients from prehospital care to rehabilitation. All this evidence will be used to benchmark performance between SHAs, Trusts, MTCs, TUs, Ambulance Trusts, and rehabilitation units at a regional and national level. The role of the National Institute of Health and Clinical Excellence (NICE) in accordance with the DoH will be to develop the long-anticipated standards of trauma care, monitor their effectiveness, and propose changes in due time. The function of the MTCs and TUs is expected to be revalidated and monitored based on the TARN evidence, and key performance indexes in comparison to their peers and international standards regarding mortality, length of hospital stay, patient-reported outcome measures and trauma-specific outcome measures that will be introduced $[64,65]$.

The role of the trauma network in trauma-specific clinical research, education and prevention will be another basic pillar and standard item of the network's agenda [66]. Each MTC will be linked with local Comprehensive Local Research Network (CLRN) specialty groups and higher education institutions, funding bodies and National Institute of Health Research (NIHR) network, contributing substantially to the development and realisation of trauma-related research at a national level [62].

The financial aspects of this effort have also been evaluated and significant steps forward have been introduced by the National Clinical Trauma Director [65]. The calculated economic cost of the RTN implementation nationally is expected to be cost neutral, and progressively will evolve into a cost reduction system [65]. According to the Trauma Char on current figures the costs of implementation will range from $£ 1.4$ million to $£ 2$ million per MTC [67]. Their variation is attributed to the differences between the centres' present state of providing specialist services and their existing infrastructure. Further cost-effectiveness evidence based on the available data on modelling and monitoring the trauma- related burden led to the conclusion that a regional trauma system in England will be cost effective if the initial investment for the RTN full implementation nationally is less than $£ 60-70$ million [68].

Additional expenditure will be needed to cover the additional transfer costs of trauma patients (initial bypass protocols, repatriation transfers), as well as for the early ample involvement of the rehabilitation services. Evidence from the international literature suggests that with basic drives the reduction of hospital and ICU stay after the first years of the system's maturation (a period of 2-3 years) a positive income shift should occur. The increased direct medical cost due to the anticipated effect on the survivorship of the trauma population should also be evaluated, calculated and claimed in order to have a balanced economic future. A reform of the application of existing HRG-4 based on payment by results (PbR) tariffs in the case of injuries has been announced and is expected to allow the rationalisation of the hospitals reimbursement from April 2011. Crossmatching the diagnosis scores, based on the World Health Organization International Classification of Diseases, tenth edition (ICD-10), with the intervention/procedure complexity will produce a more realistic model of coding and refunding. With the centralisation of major trauma services, foreseeable improvements on length of hospital stay and outcome, in combination with the use of appropriate coding models, the RTNs will be able to sustain the new trauma services, compensating and justifying all necessary investments. In addition, critical care tariffs will be mandated as bed-day rates from April 2011, diminishing the weaknesses of the previously block contracts and allowing the expansion of ICU capacity at MTCs if and when required. From a wider perspective, using estimates from the Department of Transport [69] regarding the direct and indirect costs of each road traffic accident (RTA) victim ( $£ 1.64$ million per fatality and $£ 185,000$ per serious injury in 2007 values), and the estimated reduction in such fatalities according to the recent prediction of the National Audit Office (NAO) of 600 lives per year [39], the savings could well reach the sum of $£ 879$ million each year in England.

\section{Future challenges}

Establishment of specialist RTN services and adoption of a robust clinical governance programme can achieve significant improvements in the process of care and outcomes from severe injury [33]. The proposed inclusive system will incorporate the MTCs, local TUs, and ambulance and rehabilitation services (hospital and community) into one network directory. This seamless, linked system will optimise patient outcomes and concurrently reduce lengths of hospital stay, rationalise the 
use of intensive care beds, reduce disability and improve occupational return, with an overall improvement in patient experience.

There are a number of anticipated challenges that each of the components of the RTN will face in the near future. Further, it is expected that numerous other problems will arise that local and national leaders and stakeholders will have to overcome in this endeavour.

The biggest challenge facing the RTN is to constructively utilise the diversity, complexity and uniqueness of individuals and organisations in a finely tuned system for prevention of injury and provision of high quality of care for all injured patients.

In addition, financial limitations are also a major obstacle, especially if the approach to the problem is confined to a short period of time. However, in the mid to long term there is no reason that restructuring of our failing trauma services will not be proven cost effective at local, regional and national levels [38].

Another critical point with regard to the excellent paradigm of the London RTNs, the pioneers of this national trauma reformation, is that certain lessons can be learnt even though a complete replication of their model in other regions of the UK would be impractical. The dense urban character of the capital is not met even in other large urban areas of the country. Further, a significant variance can be anticipated in the sheer numbers of major trauma cases that each MTC will treat annually. The determination of whether a lower threshold of 250 cases annually [41], in order to maintain the necessary levels of readiness and expertise, is adequate or achievable, can only be verified over time.

It is clear from the international experience of regionalisation of trauma services that safe conclusions of its effectiveness at a larger or a local scale can be evaluated after the first 2-5 years of implementation $[49,50,70]$. This transitional period for the RTN system may prove to be demanding and may raise significant dilemmas and questions as to the suitability of the project for the whole of the UK, or for some of the peripheral regions. For this reason, the role of each SHA, PCT and local Trust is essential in fine tuning the general idea to accommodate the specific needs and characteristics of each region. Patience and persistence in this endeavour are of paramount importance to this mid-term to longterm investment in human resources, assets, and efforts. The foreseeable initial improvements are expected to be related to complex trauma disability rates, and secondarily to mortality.

The most unexplored component of RTN implementation is related to rehabilitation services. The existing capacities of these services in the hospital as well as in the community setting are not recorded, nor addressed in the pilot model of London, at least in comparison to the other essential aspects of RTNs. Significant variance is expected to exist between different SHAs and regions, whilst the financial aspects of their upgrading also remain unknown. The significance of rehabilitation services is crucial as its failure will lead to the early congestion and suffocation of MTCs, and will undermine the expected improvements in disability rates of the injured patients during the first years of the RTN system.

Present data recording and quality assurance are based solely on the TARN database, which under-represents the clinical reality as it collects data from the majority of but not all trauma-covering hospitals, and is mostly based around fatalities in admitted patients. Nevertheless, the quality of this database, and the support it receives from the national trauma leaders, offers a strong starting point. The incorporation of data from ambulance services and rehabilitation units is expected to produce an amalgamation of collected evidence that will surpass any previous audit attempt. Obvious organisational and administrative demands for such a task should not be underestimated, and remain unspecified in the existing RTN national plan.

\section{Conclusions}

The reform of trauma care in England, especially the care of severely injured patients, has already started, with strong clinical leadership being embraced as the way forward. There is no doubt that the trauma-related healthcare community is finally, after many years, under the spotlight. However, one may argue that the timing may not be perfect due to the current unprecedented economic climate. Moreover, the expectations are high and time is pressing. While for the first time ever a genuine political will and support exists, the changes required to maintain the momentum for the implementation of the RTN need to be marshalled against arguments, myths and perceptions from the past. Such an approach may reverse the disinterested attitudes of many, and gradually produce a cultural shift in the public, clinicians and policymakers over time. Only then can a successful implementation of the RTN concept be expected and the long-aspired optimisation of the care of traumatised patients in England attained.

\footnotetext{
Authors' contributions

NKK contributed to the design, acquisition of relative data, drafting of the manuscript. PVG contributed to the conception, design, and final drafting of the manuscript. Both authors read and approved the final manuscript.
}

Competing interests

The authors declare that they have no competing interests.

Received: 18 May 2011 Accepted: 11 November 2011

Published: 11 November 2011 


\section{References}

1. Department of Health: Saving Lives: Our Healthier Nation.[http://www. archive.official-documents.co.uk/document/cm43/4386/4386-00.htm].

2. Department of Health: Health Profile of England, 2008.[http://www.dh.gov. uk/en/Publicationsandstatistics/Publications/PublicationsStatistics/ DH_093465].

3. Department of Transport: Reported Road Casualties Great Britain. 2008 [http://www.dft.gov.uk/pgr/statistics/datatablespublications/accidents/ casualtiesgbar/rrcgb2008]

4. Office for National Statistics: Mortality statistics. Injury and poisoning Review of the Registrar General on deaths attributed to injury and poisoning in England and Wales. 2009 [http://www.ons.gov.uk/ons/rel/ vsob1/injury-and-poisoning-mortality-in-england-and-wales/2009/index. html].

5. Office for National Statistics: Mortality Statistics: Injury and Poisoning, England and Wales (Series DH4: discontinued). Review of the Registrar General on deaths attributed to injury and poisoning in England and Wales. 2004 [http://www.ons.gov.uk/ons/publications/index.html?pageSize = 50\&newquery=Review-of-the-Registrar-General-on-deaths-attributed-toinjury-and-poisoning-in-England-and-Wales].

6. National Confidential Enquiry into Patient Outcome and Death: Trauma: who cares?[http://www.ncepod.org.uk/2007t.htm].

7. The Royal College of Surgeons of England: Regional trauma systems: Interim guidance for commissioners.[http://www.rcseng.ac.uk/ publications].

8. Baker SP, O'Neill B: The injury severity score: an update. J Trauma 1976, 16:882-885.

9. Association for the Advancement of Automotive Medicine: The Abbreviated Injury Scale. Des Plaines, IL USA: Association for the Advancement of Automotive Medicine; 1990.

10. Soreide K: Epidemiology of major trauma. Br J Surg 2009, 96:697-698.

11. Accident Services Review Committee of Great Britain and Ireland: Interim Report of the Review Committee on Accident Services of Great Britain and Ireland London, UK: British Medical Association; 1961.

12. Accident Services Review Committee of Great Britain and Ireland: Accident Services of Great Britain and Ireland: Second Report London, UK: British Medical Association; 1965.

13. Accident Services Review Committee of Great Britain and Ireland: Report of a Working Party on Progress in the Provision of Accident Services London, UK: British Medical Association; 1970.

14. Cales $\mathrm{RH}$, Trunkey DD: Preventable trauma deaths. A review of trauma care systems development. JAMA 1985, 254:1059-1063.

15. The Royal College of Surgeons of England: Report of the working party on the management of patients with major injuries [http://www.rcseng.ac.uk/ publications].

16. Anderson ID, Woodford M, de Dombal FT, Irving M: Retrospective study of 1000 deaths from injury in England and Wales. Br Med J (Clin Res Ed) 1988, 296:1305-1308

17. The British Orthopaedic Association: The Management of Trauma in Great Britain.[http://www.boa.ac.uk/site/showpublications.aspx?id = 59].

18. Redmond AD: The North Staffordshire trauma system. J R Coll Surg Edinb 1993, 38:248-250.

19. National Audit Office: NHS Accident and Emergency Departments in England.[http://www.nao.org.uk/publications/archive/9293.aspx].

20. The British Orthopaedic Association: The Management of Skeletal Trauma in the United Kingdom.[http://www.boa.ac.uk/site/showpublications.aspx? id $=59]$.

21. Yates DW, Woodford M, Hollis S: Preliminary analysis of the care of injured patients in 33 British hospitals: first report of the United Kingdom major trauma outcome study. BMJ 1992, 305:737-740.

22. Lecky F, Woodford M, Yates DW: Trends in trauma care in England and Wales 1989-97. UK Trauma Audit and Research Network. Lancet 2000, 355:1771-1775.

23. Rowley DI: Trauma and trauma management. J R Coll Surg Edinb 1993, 38:246-247.

24. Nicholl J, Turner J: Effectiveness of a regional trauma system in reducing mortality from major trauma: before and after study. BMJ 1997, 315:1349-1354.

25. The British Orthopaedic Association: The Care of Severely Injured Patients in the United Kingdom.[http://www.boa.ac.uk/site/showpublications.aspx? $\mathrm{id}=59]$.
26. The British Orthopaedic Association: Better Care for the Severely Injured A joint report from the Royal College of Surgeons of England and the British Orthopaedic Association.[http://www.rcseng.ac.uk/publications/ docs/severely_injured.html].

27. Lecky FE, Woodford M, Bouamra O, Yates DW: Lack of change in trauma care in England and Wales since 1994. Emerg Med J 2002, 19:520-523.

28. National Audit Office: Improving Emergency Care in England. Report by the Comptroller and Auditor General.[http://www.publications.parliament. uk/pa/cm200405/cmselect/cmpubacc/445/445.pdf].

29. Darzi A: Healthcare for London: A Framework for Action. NHS for London.[http://www.london.nhs.uk/news-and-health-issues/press-releases/ archive/healthcare-for-london:-a-framework-for-action].

30. Department of Health: High Quality Care for All. NHS next stage review final report.[http://www.dh.gov.uk/en/Publicationsandstatistics/Publications/ PublicationsPolicyAndGuidance/DH_085825]

31. The Royal College of Surgeons of England: The Intercollegiate Group on Trauma Standards: Regional trauma systems. interim guidance for commissioners.[http://www.rcseng.ac.uk/publications].

32. London Trauma Office: London's new Trauma system.[http:// healthcareforlondon.steel-Itd.com/assets/Major-trauma/LTO-factsheet060410. pdf].

33. Davenport RA, Tai N, West A, Bouamra O, Aylwin C, Woodford M, McGinley A, Lecky F, Walsh MS, Brohi K: A major trauma centre is a specialty hospital not a hospital of specialties. Br J Surg 2010, 97:109-117.

34. Bircher M, Giannoudis PV: Pelvic trauma management within the UK: a reflection of a failing trauma service. Injury 2004, 35:2-6.

35. Giannoudis PV: Optimising the management of the injured patient. Injury 2007, 38:1113-1114.

36. Giannoudis PV: Editorial - Management of patients with multiple injuries: looking ahead to the future. Injury 2009, 40(Suppl 4):S1-4.

37. Giannoudis PV: Trauma care in the UK and beyond: what are the issues? Injury 2009, 40:681-682

38. Giannoudis PV, Kanakaris NK: The unresolved issue of health economics and polytrauma: the UK perspective. Injury 2008, 39:705-709.

39. National Audit Office: Major trauma care in England. Report by the Comptroller and Auditor General.[http://www.nao.org.uk/publications/ 0910/major_trauma_care.aspx].

40. The Royal College of Surgeons of England and the British Orthopaedic Association: Better Care for the Severely Injured. A Joint Report from the Royal College of Surgeons of England and the British Orthopaedic Association.[http://www.rcseng.ac.uk/publications].

41. American College of Surgeons Committee on Trauma: Resources for the Optimal Care of the Injured Patient Chicago, IL, USA: American College of Surgeons; 2006.

42. Edwards A, Di Bartolomeo S, Chieregato A, Coats T, Della Corte F, Giannoudis P, Gomes E, Groenborg H, Lefering R, Leppaniemi A, Lossius HM, Ortenwal P, Roise O, Rusnak M, Sturms L, Smith M, Bondegaard Thomsen A, Willett K, Woodford M, Yates D, Lecky F: A comparison of European Trauma Registries. The first report from the EuroTARN Group. Resuscitation 2007, 75:286-297.

43. Kuhne CA, Mand C, Sturm J, Lackner CK, Kunzel A, Siebert H, Ruchholtz S: The Trauma Network of the German Society for Trauma 2009 [in German]. Unfallchirurg 2009, 112:878-884.

44. Mullins RJ, Mann NC: Population-based research assessing the effectiveness of trauma systems. J Trauma 1999, 47(Suppl):S59-66.

45. Papathanasopoulos A, Nikolaou V, Petsatodis G, Giannoudis PV: Multiple trauma: an ongoing evolution of treatment modalities? Injury 2009, 40:115-119.

46. Sampalis JS, Denis R, Lavoie A, Fréchette P, Boukas S, Nikolis A, Benoit D, Fleiszer D, Brown R, Churchill-Smith M, Mulder D: Trauma care regionalization: a process-outcome evaluation. J Trauma 1999, 46:565-579.

47. Schneppendahl J, Lefering R, Kuhne CA, Ruchholz S, Hakimi M, Witte I, Logters T, Windolf J, Flohe S: Interhospital transfer of severely injured patients in Germany: Evaluation of the DGU trauma register [in German]. Unfallchirurg

48. Utter GH, Maier RV, Rivara FP, Mock CN, Jurkovich GJ, Nathens AB: Inclusive trauma systems: do they improve triage or outcomes of the severely injured? J Trauma 2006, 60:529-535.

49. West JG, Cales RH, Gazzaniga AB: Impact of regionalization. The Orange County experience. Arch Surg 1983, 118:740-744. 
50. West JG, Trunkey DD, Lim RC: Systems of trauma care. A study of two counties. Arch Surg 1979, 114:455-460.

51. Subcommittee of the American College of Surgeons Committee on Trauma: Trauma Performance Improvement Reference Manual Chicago, IL, USA: American College of Surgeons; 2002.

52. The Royal College of Surgeons of England: Provision of Trauma Care: Policy Briefing [http://www.rcseng.ac.uk/news/docs/FINAL\%20trauma\%20statement \%207\%20sept\%2007.pdf/].

53. Nathens AB, Jurkovich GJ, Maier RV, Grossman DC, Mackenzie EJ, Moore M, Rivara FP: Relationship between trauma center volume and outcomes. JAMA 2001, 285:1164-1171.

54. Bennett KM, Vaslef S, Pappas TN, Scarborough JE: The volume-outcomes relationship for United States Level I trauma centers. J Surg Res 2011, 167:19-23.

55. Hettiaratchy S, Tai N, Mahoney P, Hodgetts T: UK's NHS trauma systems: lessons from military experience. Lancet 2010, 376:149-151.

56. Ramasamy A, Hinsley DE, Edwards DS, Stewart MP, Midwinter M, Parker PJ Skill sets and competencies for the modern military surgeon: lessons from UK military operations in Southern Afghanistan. Injury 2009, 41:453-459.

57. Smith JE: Self-assessment questions in the management of major trauma. J R Army Med Corps 2004, 150:200-204.

58. Smith J, Hodgetts T, Mahoney P, Russell R, Davies S, McLeod J: Trauma governance in the UK defence medical services. J R Army Med Corps 2007, 153:239-242.

59. Hjortdahl M, Ringen AH, Naess AC, Wisborg T: Leadership is the essential non-technical skill in the trauma team-results of a qualitative study. Scand I Trauma Resusc Emerg Med 2009, 17:48.

60. Happel O, Papenfuss T, Kranke P: Training for real: simulation, teamtraining and communication to improve trauma management [in German]. Anasthesiol Intensivmed Notfallmed Schmerzther 2010, 45:408-415.

61. NHS: Major Trauma: Towards Excellence.[http://www.excellence. eastmidlands.nhs.uk/welcome/improving-care/emergency-urgent-care/ major-trauma/].

62. NHS Clinical Advisory Groups (CAG) Report: Regional Networks for Major Trauma.[http://www.excellence.eastmidlands.nhs.uk/welcome/improvingcare/emergency-urgent-care/major-trauma/major-trauma-relateddocuments/l.

63. Trauma Audit \& Research Network: Trauma Care in England and Wales. Hope Hospital, University of Manchester.[https://www.tarn.ac.uk/content. aspx?ca=15].

64. Willett K, Marsh D, Moran C, Giannoudis P, Bircher M: British Orthopaedic Association standards for trauma. J Bone Joint Surg Br 2009, 91:985-986.

65. UK Department of Health: Professor Keith Willett, National Clinical Director for Trauma Care.[http://www.dh.gov.uk/en/Aboutus/ MinistersandDepartmentLeaders/Nationalclinicaldirectors/DH_101369].

66. Willett KM, Gray B, Moran CG, Giannoudis PV, Pallister I: Orthopaedic trauma research priority-setting exercise and development of a research network. Injury 2010, 41:763-767.

67. Willett K: Finance Advice on Regional Trauma Networks (RTN).[http:// www.excellence.eastmidlands.nhs.uk/welcome/improving-care/emergencyurgent-care/major-trauma/major-trauma-related-documents/].

68. Nicholl J, Young T, Pickering A, Turner J, Goodacre S: The costeffectiveness of regional trauma networks in England.[http://www. excellence.eastmidlands.nhs.uk/welcome/improving-care/emergency-urgentcare/major-trauma/major-trauma-related-documents/].

69. Department for Transport: Fatalities in reported road accidents. 2009 [http://www.dft.gov.uk/pgr/statistics/datatablespublications/accidents/]

70. Cales RH: Trauma mortality in Orange County: the effect of implementation of a regional trauma system. Ann Emerg Med 1984, 13:1-10

Pre-publication history

The pre-publication history for this paper can be accessed here: http://www.biomedcentral.com/1741-7015/9/121/prepub

doi:10.1186/1741-7015-9-121

Cite this article as: Kanakaris and Giannoudis: Trauma networks: present and future challenges. BMC Medicine 2011 9:121.

\section{Submit your next manuscript to BioMed Central and take full advantage of:}

- Convenient online submission

- Thorough peer review

- No space constraints or color figure charges

- Immediate publication on acceptance

- Inclusion in PubMed, CAS, Scopus and Google Scholar

- Research which is freely available for redistribution

Submit your manuscript at www.biomedcentral.com/submit
Ciomed Central 